\title{
Desain Aplikasi Sistem Pendaftaran Online Menggunakan Smartphone Untuk Meningkatkan Mutu Pelayanan pada Rumah Sakit
}

\author{
Fuaida Nabyla ${ }^{1}$, Rito Cipta Sigitta Hariyono ${ }^{2}$ \\ Universitas Peradaban Prodi Teknik Informatika, FST, \\ Jalan Raya Pagojengan KM.3, Kec. Paguyangan, KabupatenBrebes \\ email : ${ }^{1}$ nabylafuaida614@gmail.com, ${ }^{2}$ ritocipta@peradaban.ac.id
}

Diterima: 12 Oktober 2019; Direvisi: 22 Nopember 2019; Disetujui: 25 Nopember 2019

\begin{abstract}
Abstrak
Sejalan dengan perkembangan di dunia teknologi yang semakin pesat, teknologi informasi juga salah satu tools untuk membantu meningkatkan pelayanan bagi rumah sakit khususnya dalam layanan pendaftaran pasien dan menunggu antrian. Tidak ada informasi yang terkait nomor antrian ke berapa yang sedang dan akan dilayani dan tidak adanya integrasi data dari sistem pendaftaran, rekam medis dan layanan poliklinik menjadikan pasien cepat jenuh dan tidak efisien. Maka peneliti mengembangkan desain sistem pendaftaran dengan metode yang digunakan adalah Design Science Research Methodology (DSRM), sebuah metodologi yang berorentasikan desain informasi sistem. Desain sistem pendaftaran ini merupakan aplikasi online berbasis smartphone yang dapat diakses oleh pasien untuk melakukan pendaftaran layanan kesehatan di rumah sakit. Sehingga proses antrian pendaftaran menjadi efektif karena sistem ini memiliki fitur notifikasi yang memberikan informasi nomer antrian dan perkiraan waktu kapan nomer antrian dilayani. Tentunya ini memberikan kemudahan bagi pasien untuk mendaftar dan mengatur antrian.
\end{abstract}

Kata kunci: Aplikasi Marvel, Balsamiq Mockup, Design Science Research Methodology

\begin{abstract}
In line with developments in the world of technology that is increasingly fast, information technology is also one tool to help improve services for hospitals specialized inpatient registration services and waiting in line. there is no information regarding the number of queuing numbers that are being and will be announced and no data from the registration system, medical records, and polyclinic services makes patients quickly saturated and inefficient. Then the researcher developed the registration system design with the method used was the Design Research Methodology Science (DSRM), a study that oriented the design of information systems. The design of this registration system is a smartphone-based online application that can be accessed by patients to register for health services at the hospital. Request the queue registration process to be effective because this system has a notification feature that provides queue number information and estimates the time whenever the queue number is served. Surely this makes it easy for patients to register and prepare queues.
\end{abstract}

Keywords: Marvel Application, Balsamiq Mockup, Design Science Research Methodology 


\section{PENDAHULUAN}

Pada era sekarang ini hampir setiap orang menuntut pelayanan publik yang semakin efisien, salah satunya pelayanan kesehatan di lingkungan Rumah Sakit. "Rumah sakit adalah institusi pelayanan kesehatan yang menyelenggarakan pelayanan kesehatan perorangan secara paripurna yang menyediakan pelayanan rawat inap, rawat jalan dan gawat darurat"[1]. Pelayanan yang baik merupakan kunci untuk menarik minat konsumen dan mempertahankannya, dengan pelayanan yang baik dapat menciptakan kepuasan konsumen yang mengarah pada ketahanan dan loyalitas konsumen [2]. Semakin bertambahnya populasi di dunia maka jumlah antrian dan panjang antrian juga akan semakin bertambah. Dalam dunia usaha, bertambahnya pelanggan berarti bertambah pula transaksi usaha [3]. Antrian adalah suatu fenomena yang timbul pada aktivitas hidup manusia, antrian awalnya muncul karena disebabkan oleh aktivitas pelayanan yang tidak diimbangi oleh kebutuhan akan pelayanan sehingga pengguna layanan tersebut tidak terlayani dengan segera. Menunggu merupakan kegiatan yang membosankan, seperti menunggu giliran pelayanan di rumah sakit, khususnya pada poliklinik rawat jalan. Hal ini merupakan salah satu faktor yang mempengaruhi kepuasan pasien. Waktu tunggu yang lama akan mengurangi kenyamanan pasien dan berpengaruh pada keputusan pasien di masa mendatang [4]. Dengan adanya masalah tersebut, maka rumah sakit dituntut untuk menciptakan prosedur agar pasien tidak menunggu lama ketika ingin mendapatkan pelayanan. Antrian muncul disebabkan oleh aktivitas pelayanan yang tidak diimbangi oleh kebutuhan akan pelayanan sehingga pengguna layanan tersebut tidak terlayani dengan segera [2]. Hasil observasi beberapa rumah sakit menggunakan metode pengumpulan data dan wawancara terkait pelayanan pasien pada sistem pendaftaran, rekam medis dan sistem antrian tunggu layanan yang masih menggunakan sistem manual mengakibatkan terjadinya pemborosan waktu, biaya, dan tenaga.

Sejalan dengan perkembangan di dunia teknologi yang semakin pesat, teknologi informasi termasuk salah satu tools untuk membantu meningkatkan pelayanan bagi rumah sakit, salah satunya dalam layanan pendaftaran pasien dan menunggu antrian layanan kesehatan agar pasien mendapatkan pelayanan yang baik dan terarah. Sistem informasi didefinisikan secara teknis sebagai seperangkat komponen yang saling terkait yang mengumpulkan (atau mengambil), memroses, menyimpan, dan mendistribusikan informasi untuk mendukung pengambilan keputusan dan pengendalian dalam suatu organisasi [5]. Tahap-tahap ini menentukan bagaimana system akan beroperasi dari segi penempatan hardware, software, dan infrastruktur network; user interface; forms, dan report yang digunakan; dan program, database, files tertentu yang dibutuhkan [6]. Dari permasalahan tersebut, maka terdapat pertanyaan penting: (1). Bagaimana membangun dan mengembangkan sistem pendaftaran pasien layanan poliklinik di RSUI Harapan Anda yang memberikan kemudahan bagi pasien dalam proses pendaftaran dan menunggu antrian; (2). Bagaimana desain sistem pendaftaran online pasien layanan poliklinik RSUI Harapan Anda dengan menggunakan smartphone yang memberikan informasi antrian dan perkiraan waktu kapan nomer antrian dilayani. Hasil dari penelitian ini diharapkan memberikan kontribusi pada pengembangan dan pengaplikasian ilmu di bidang informatika serta memberikan kontribusi pada rumah sakit untuk meningkatkan mutu pelayanan khususnya dalam sistem pendaftaran pasien dan antrian.

\section{METODE PENELITIAN}

Design Science Research Methodology (DSRM) adalah sebuah metodologi yang berorientasi desain sistem informasi. DSRM juga merupakan kerangka prosedur yang digunakan untuk mempermudah penelitian di bidang teknologi informasi yang digunakan sebagai proses pemahaman serta mengulas untuk mengenali dan mengevaluasi hasil penelitian. Design Science Research Methodology (DSRM) terdiri dari enam tahapan yang harus dilakukan, yaitu problem identification and motivation (identifikasi masalah dan motivasi), 
objective of the solution (mendefinisikan objek dari solusi permasalahan), design and development (perencanaan dan pengembangan), demonstration (demonstrasi), evaluation (evaluasi) dan communication (komunikasi) [7]. Tahapan-tahapan tersebut diilustrasikan pada gambar 1.

Proses identifikasi masalah dilakukan pada bagian pelayanan poliklinik dengan melakukan pengumpulan data dengan cara : (1). Observasi. Peneliti memposisikan diri sebagai pengamat dimana proses pengamatan dilakukan secara langsung di Rumah Sakit Umum Islam Harapan Anda Tegal; (2). Wawancara. Wawancara merupakan salah satu bentuk teknik pengumpulan data dengan melalui tanya jawab dengan pengelola pihak IT dari RSUI Harapan Anda. Metode wawancara digunakan guna memperoleh keterangan tentang beberapa data atau hal-hal yang diperlukan dalam penelitian.

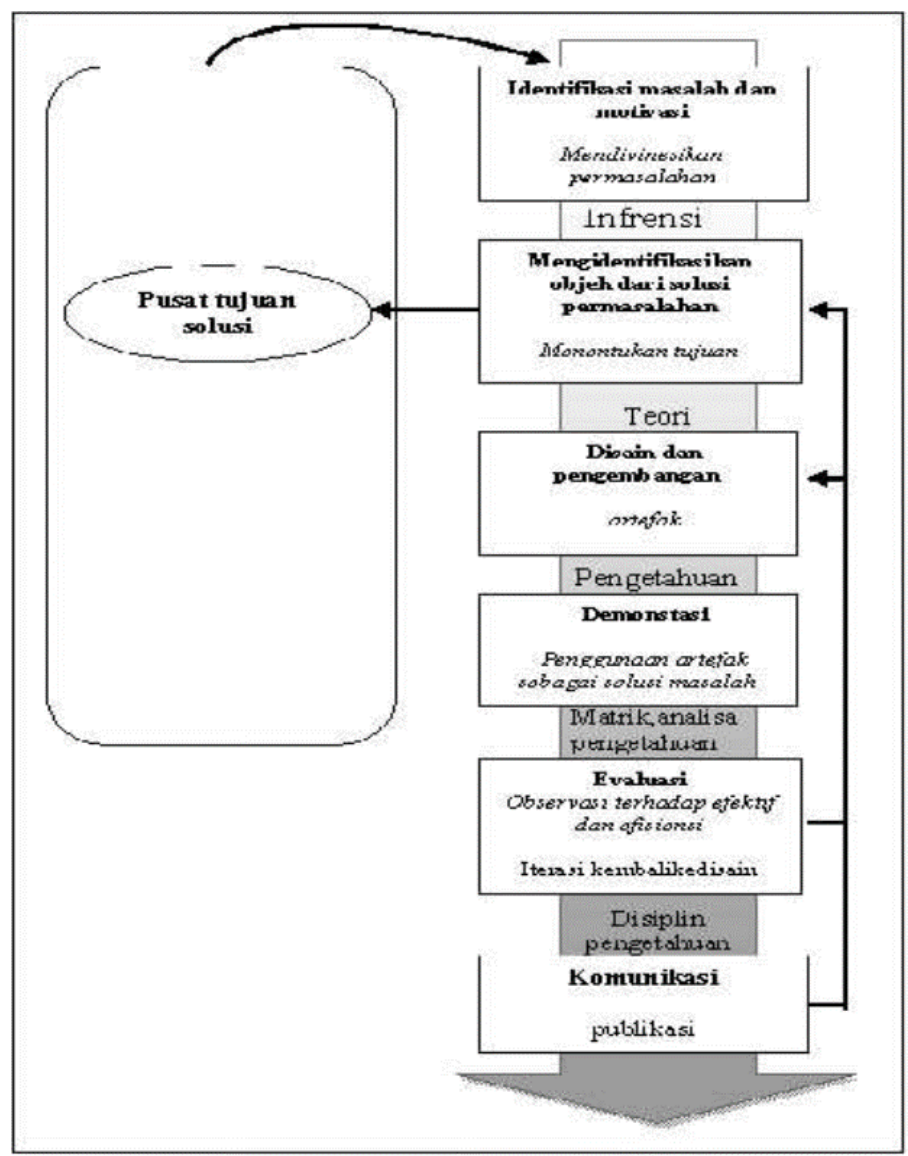

Gambar 1. Tahapan Metodologi Penelitian

Proses identifikasi masalah menghasilkan output berupa beberapa point masalah yang sedang dihadapi pihak layanan poli RSUI Harapan Anda. Identifikasi masalah yang dilakukan dengan metode wawancara, dilakukan dengan cara membuat forum diskusi FGD (focus group discussion), bersama-sama antara peneliti dengan pihak manajemen rumah sakit yang terkait dengan masalah yang akan diselesaikan. Hasil dari FGD ini berupa kesimpulan yang menjelaskan masalah, tujuan dari solusi dan pengetahuan tentang apa yang mungkin dan layak untuk dijadikan solusi. Hasil dari FGD dijadikan acuan bagi peneliti untuk membuat desain sistem yang berupa flowchart. Flowchart dibuat untuk menggambarkan alur sistem yang akan dikembangkan. Berdasarkan flowchart tersebut, peneliti melanjutkan proses dengan membuat desain prototype sistem antrian yang disesuaikan dengan sistem pendaftaran pasien. Desain prototipe ini dibuat dengan menggunakan aplikasi desain mock up sebagai bentuk sistem informasi yang diminta serta menggunakan aplikasi desain marvell untuk simulasi perancangan program. Setelah mengembangkan atau membuat desain prototipe dengan mock up, kemudian 
desain tersebut dipresentasikan kepada pengelola layanan IT di RSUI Harapan Anda dengan menggunakan aplikasi marvell melalui smartphone untuk memudahkan pihak IT mengembangkan program dari desain prototipe yang telah dilakukan serta memberitahukan tentang bagaimana menggunakan program dalam memecahkan masalah. Hasil pengamatan dan evaluasi sistem dilakukan oleh pihak IT RSUI Harapan Anda, apakah sistem sudah sesuai dengan yang di harapakan oleh pihak pengelola layanan IT RSUI Harapan Anda atau belum. Tujuan lain dari tahapan ini adalah untuk mengamati dan mengukur seberapa baik solusi ini untuk menyelesaikan masalah yang ada. Selain itu, pihak pengelola layanan IT RSUI Harapan Anda juga memberikan penilaian berupa kendala-kendala yang dihadapi saat menggunakan program ini, serta masalah-masalah yang mungkin muncul nantinya. Hasil evaluasi yang berkaitan dengan masalah dan solusi di atas di dokumentasikan dan dijadikan laporan untuk melanjutkan proses pengmebangan sistem.

\section{HASIL DAN PEMBAHASAN}

Proses observasi dilakukan langsung di lapangan, dimulai dari registrasi pasien, aktifitas rekam medis, dan melakukan wawancara dengan pasien saat aktifitas menunggu antrian panggilan di ruang tunggu bagian pelayanan poliklinik. Hasil dari identifikasi masalah dijelaskan pada tabel 1 sebagai berikut :

Tabel 1. Identifikasi masalah

\begin{tabular}{ll}
\hline \multicolumn{1}{c}{ Aktivitas } & \multicolumn{1}{c}{ Identifikasi Masalah } \\
\hline Registrasi pasien & - Proses pendaftaran untuk mendapakan antrian pelayanan poli \\
& klinik masih dilakukan secara manual \\
& - Waktu pendaftaran secara manual masih cukup lama, sekitar 7 \\
& -10 menit karena data di input oleh petugas registrasi \\
& sehingga harus antri. \\
Aktivitas rekam medis & - Sistem Informasi Pendaftaran Rekam Medis belum terintegrasi \\
& - ke Pelayanan Poli (Nomer Antrian) \\
Aktifitas menunggu panggilan & - Pemanggilan masih manual \\
& - Sering terjadi pemanggilan yang berulang \\
& - Tidak adanya kepastian pemanggilan pasien \\
& - Tidak adanya monitor aktivitas antrian \\
& Terjadinya pemborosan waktu
\end{tabular}

Dari hasil FGD ada beberapa identifikasi masalah yang bisa diselesaikan dengan solusi yang sama, sehingga nantinya pada proses ini, 8 (delapan) masalah yang sudah didefenisikan akan dikerucutkan menjadi 4 (empat) definisi masalah, seperti proses pendaftaran untuk mendapakan nomer antrian pelayanan poli masih dilakukan secara manual dan waktu pendaftaran yang masih cukup lama sekitar 7-10 menit bisa dibuatkan solusi yang sama yaitu input data pasien yang dilakukan secara online dan terintegrasi langsung ke sistem rekam medis. Tabel 2 menunjukkan definisi masalah dan solusi hasil dari FGD yang telah dilakukan:

Tabel 2. Definisi masalah

\begin{tabular}{ll}
\hline \multicolumn{1}{c}{ Hasil Identifikasi } & \multicolumn{1}{c}{ Solusi yang akan terlaksana } \\
\hline Proses pendaftaran untuk mendapakan & Input data pasien akan bersifat online, data pasien \\
antrian pelayanan poli masih dilakukan & terntegrasi langsung ke sistem rekam medis, sehingga \\
secara manual & mengurangi pemborosan waktu \\
Sistem informasi pendaftaran rekam medis & $\begin{array}{l}\text { Sistem registrasi pendaftaran secara otomatis akan } \\
\text { memberikan nomer antrian kepada pasien setelah }\end{array}$ \\
\hline
\end{tabular}


belum terintegrasi ke pelayanan poliklinik

mendaftar online, kemudian data pasien yang mendaftar akan dikelola oleh pihak rekam medik dan akan dikirim ke bagian pelayanan poliklinik sesuai antrian poliklinik yang dituju pasien.

Pemanggilan masih manual

Perawat setiap layanan poliklinik hanya duduk di depan sistem untuk memantau pasien yang dilayani serta yang akan di layani berdasarkan daftar antrian yang sudah ada.

Tidak adanya estmasi waktu pemanggilan

Setelah pasien mendapatkan nomer antrian untuk pelayanan poliklinik yang dituju. Pasien akan mengetahui antrian ke berapa yang sedang dilayani dengan melihat tampilan dari display monitor yang tersedia di beberapa tempat yang ada di Rumah sakit, dengan adanya informasi tersebut akan memudahkan pasien saat menunggu pelayanan poliklinik dan dapat di akses urutan antrian melalui smartphone

Skema pendaftaran menggunakan smartphone diawali dengan aplikasi yang sudah terinstall di smartphone pasien kemudian mengisi form pendaftaran berikut tampilan proses pengisian form pendaftaran dengan menggunakan basis data smartphone menggunakan mockup seperti ditampilkan pada Gambar 2.

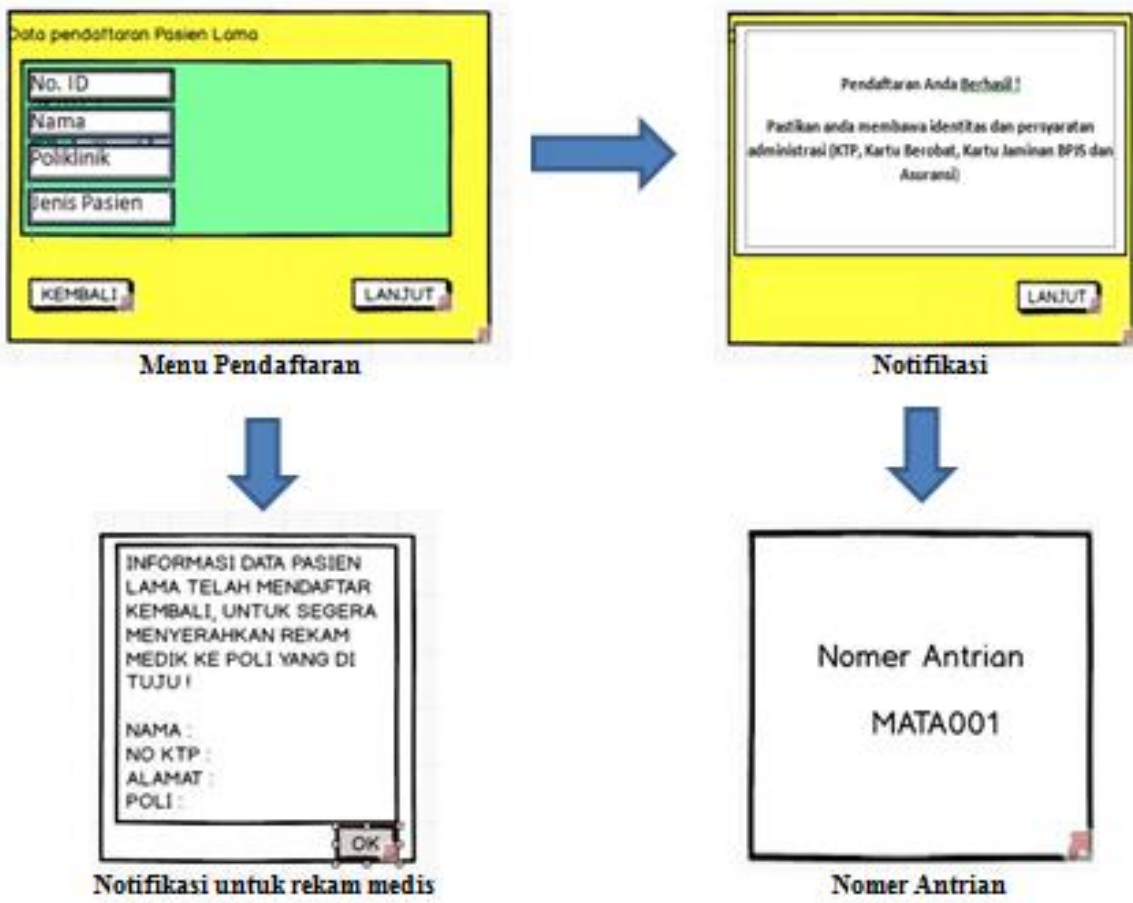

Gambar 2. Proses pendaftaran online

Setelah pasien mendapatkan nomer antrian, maka secara otomatis pada display monitor ruang tunggu menampilkan informasi pasien yang sedang di layani dan akan di layani pada setiap poli pelayanan di rumah sakit harapan anda seperti pada Gambar 3. 

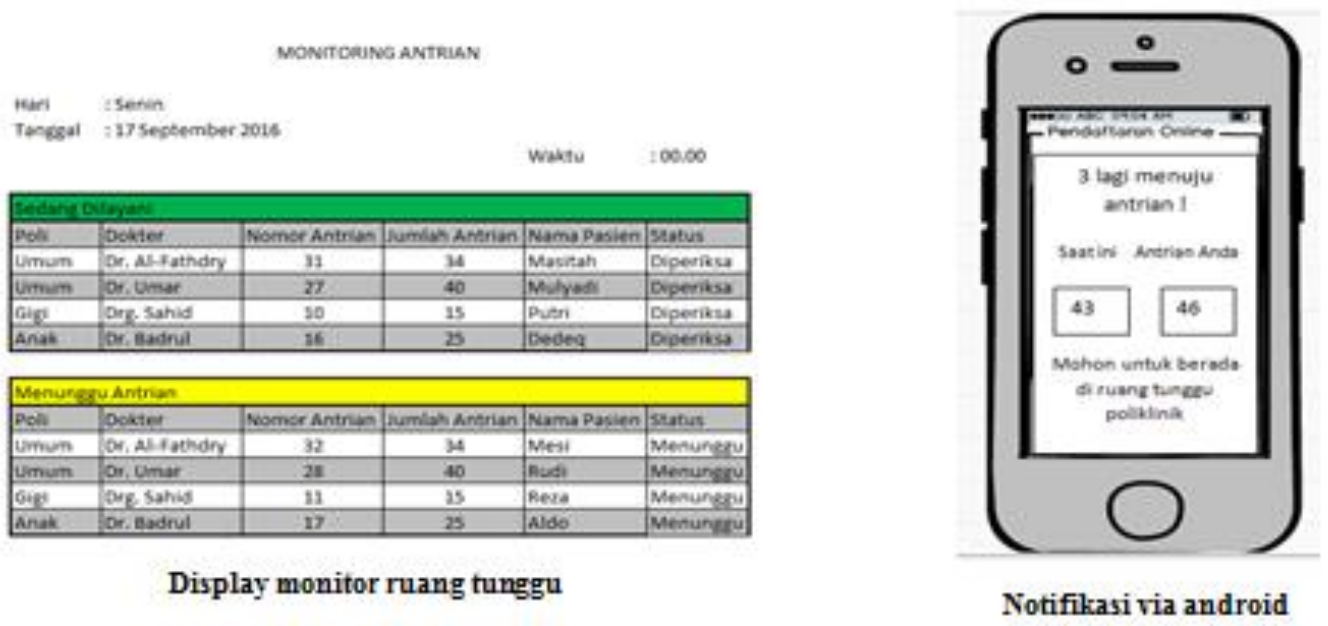

Gambar 3. Monitoring antrian dan notifikasi antrian

Pemberitahuan atau notifikasi kepada pasien yang mendaftar secara online bertujuan agar pasien yang nomer antriannya akan segera dipanggil supaya bersiap-siap untuk berada dekat ruang poliklinik yang dituju sehingga ketika nomer antriannya dipanggil bisa langsung masuk ruang dokter dan lebih efisien dalam hal waktu dan petugas tidak perlu melakukan pemanggilan berulang. Notifikasi ini akan muncul pada saat 3 (tiga) nomer antrian sebelum antrian pasien. Setelah proses Design and Development dengan membuat skema interaksi dan Design dengan menggunakan mock up selesai, maka selanjutnya dilakukan proses demonstrasi menggunakan aplikasi marvell. Demonstrasi ini dilakukan kepada pihak IT rumah sakit sebagai pihak yang akan menjadi operator untuk system ini kedepan nantinya. Tentunya pada saat proses demonstrasi system yang dibuat sudah benar-benar real sehingga pihak IT rumah sakit bisa memberikan masukan-masukan untuk bahan evaluasi nantinya dan juga untuk memberitahukan kendala-kendala apa saja yang bakal dihadapi nantinya.

1) Implementasi tampilan awal, proses login, dan input data
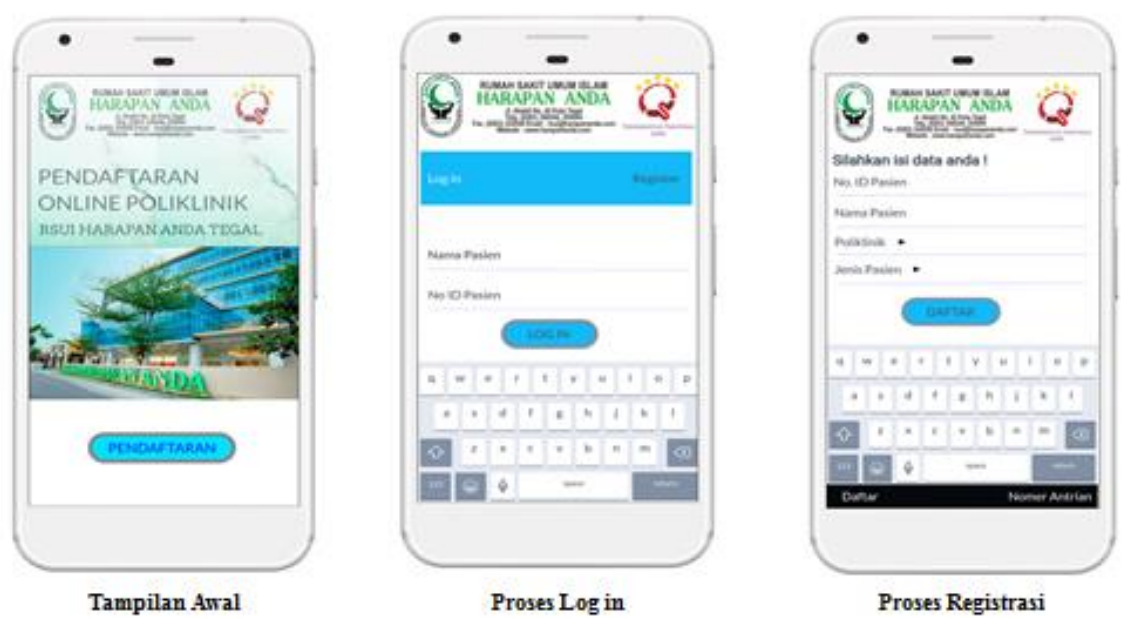

Gambar 4. Proses log in dan pendaftaran online

2) Implementasi nomer antrian, notifikasi nomer antrian dan pendaftaran berhasil 

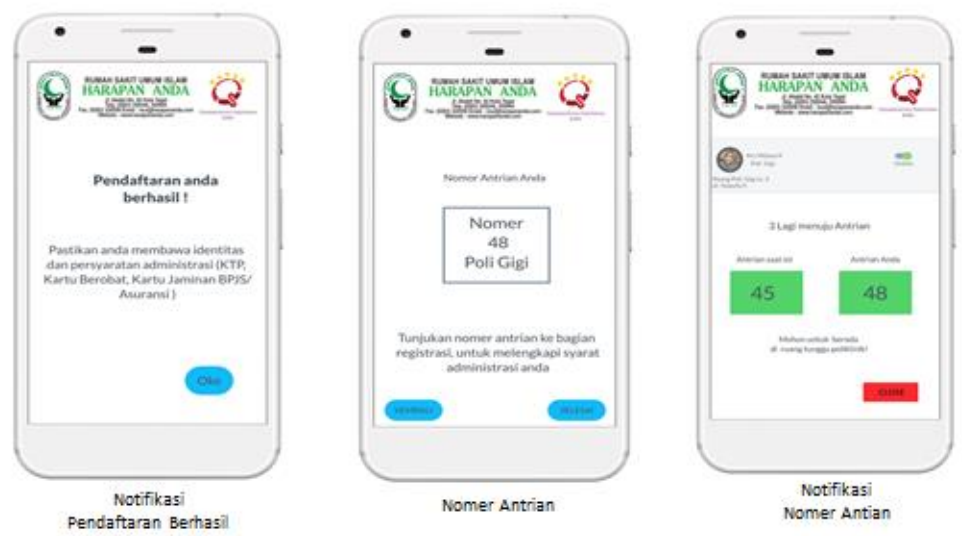

Gambar 5. Nomer antrian dan notifikasi antrian online

Evaluasi sistem dilakukan oleh pihak IT RSUI Harapan Anda sebagau user. User mengamati dan mengukur seberapa baik solusi ini untuk menyelesaikan masalah yang ada. User juga memberikan penilaian berupa kendala-kendala yang dihadapi saat menggunakan program ini, serta masalah-masalah yang mungkin muncul nantinya. Berikut adalah program atau konsep yang dihasilkan setelah dilakukan evaluasi bersama pihak rumah sakit :

1) Skema Pendaftaran sebelum dan setelah dievaluasi.

Konsep awal skema pendaftaran online untuk pasien bisa dilakukan menggunakan android dan dashboard yang ada di rumah sakit. Setelah pasien mendaftar secara online melalui aplikasi, pasien tidak langsung mendapatkan nomer antrian. Setelah di evaluasi, ternyata konsep ini sangat tidak efektif, membutuhkan proses yang lama dan tetap saja terdapat ketidakpastian nomer antrian setelah mendafar online. Untuk selanjutnya maka dibuat konsep dimana pada saat pasien melakukan registrasi secara online melalui android maka pasien akan langsung mendapatkan nomer antrian. Selanjutnya pasien cukup melapor ke bagian registrasi untuk melapor dan menyerahkan persyaratan.

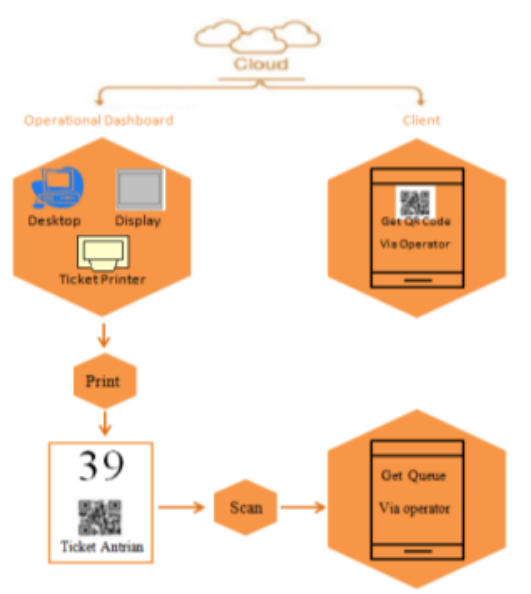

(a)

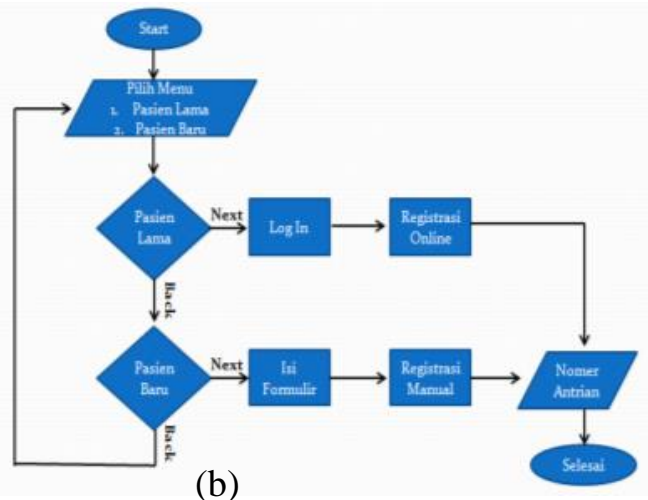

(b)

Gambar 6. Skema Pendaftaran sebelum (a) dan setelah dievaluasi (b)

2) Form registrasi online sebelum dan setelah dievaluasi.

Form registrasi online pada awalnya berisi nomor anggota, nama, dan poli. Setelah di evaluasi oleh pihak rumah sakit, harus ditambahkan jenis pasien (BPJS, Jaminan Asuransi dan Umum), karena ini merupakan SOP yang tidak bisa dilewatkan pada saat pasien 
melapor pada bagian registrasi untuk menyerahkan persyaratan. Sesuai dengan hasil diskusi dengan pihak RS, untuk tahap awal sistem ini tidak melayani pasien yang mendaftar pada beberapa hari sebelumnya. Namun untuk kedepannya akan dibuatkan halaman supaya pasien bisa mendaftar beberapa hari kedepan.

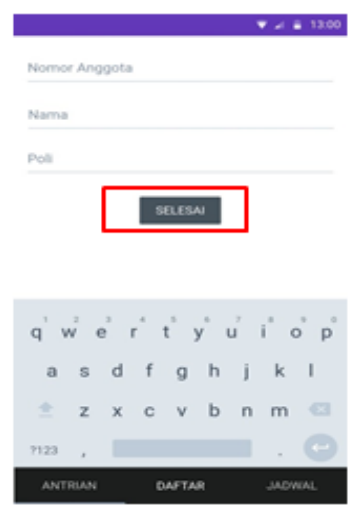

(a)

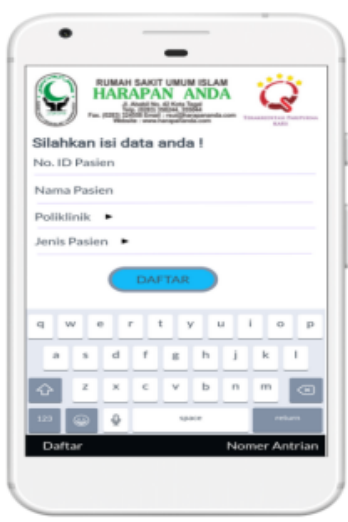

(b)

Gambar 7. Form registrasi online sebelum (a) dan setelah dievaluasi (b)

3) Notifikasi sebelum dan setelah dievaluasi

Konsep awal yang didesain untuk notifikasi hanya ditujukan kepada petugas rekam medis pada saat pasien telah berhasil mendaftar secara online yaitu "informasi data pasien lama telah mendaftar kembali, untuk segera menyerahkan rekam medis ke poli yang dituju'. Untuk notifikasi kepada pasien tidak ada. Setelah dievaluasi bersama pihak rumah sakit, disarankan untuk menambahkan notifikasi kepada pasien "pendaftaran anda berhasil !!, pastikan anda membawa identitas dan persyaratan administrasi (KTP, Kartu Berobat, Kartu Jaminan BPJS/Asuransi)", supaya pasien tidak lupa membawa persyaratan dalam bentuk hardcopy. Apabila persyaratan ini tidak bisa ditunjukan, maka pasien tidak bisa dilayani karena sebagai bukti validitas atau keaslian identitas pasien.

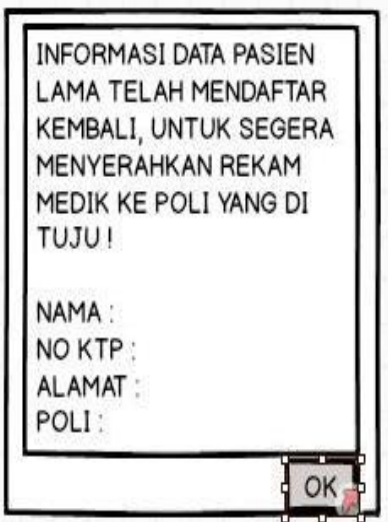

(a)

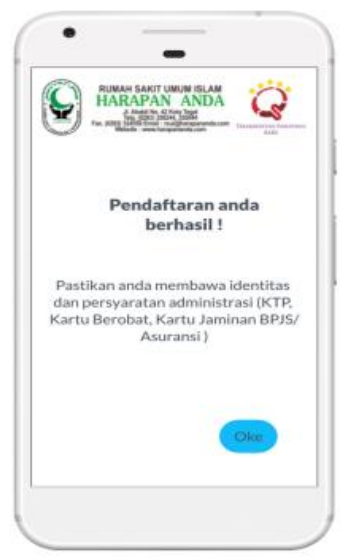

(b)

Gambar 8. Notifikasi sebelum (a) dan setelah dievaluasi (b)

4) Nomer antrian setelah dievaluasi

Setelah dilakukan evaluasi, ternyata konsep ini juga membutuhkan waktu yang lama dan proses yang panjang, sehingga nantinya teknologi pendaftaran secara online melalui android malah mempersulit pasien. Untuk itu di sarankan supaya nomer antrian didapatkan 
setelah pasien berhasil mendaftar secara online melalui android, kemudian pada handphone pasien akan langsung muncul nomer antrian sehingga pasien merasa tenang karena sudah mendapatkan nomer antrian.

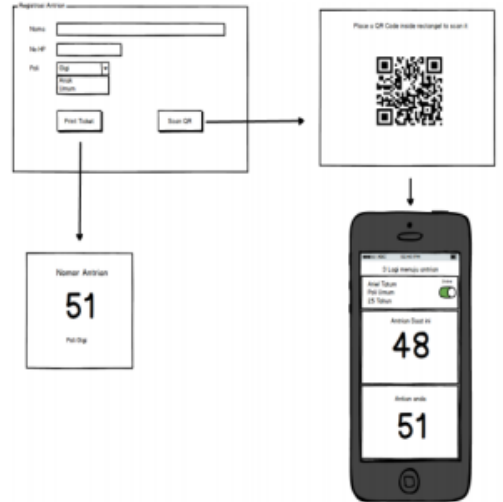

(a)

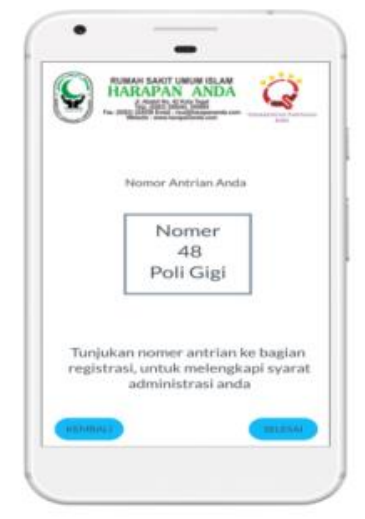

(b)

Gambar 9. Nomer antrian sebelum (a) dan setelah dievaluasi (b)

5) Desain proses registrasi akun sebelum dan setelah dievaluasi

Desain proses registrasi akun awalnya menggunakan email dan password. Setelah dievaluasi ternyata pihak rumah sakit menyarankan supaya email dihilangkan karena tidak semua pasien memiliki email, cukup dengan Nama pasien, Nomer ID Pasien dan Nomor HandPhone. Untuk memastikan proses registrasi berhasil, maka dibuat notifikasi "register akun berhasil, silahkan login untuk mendaftar pemeriksaan".

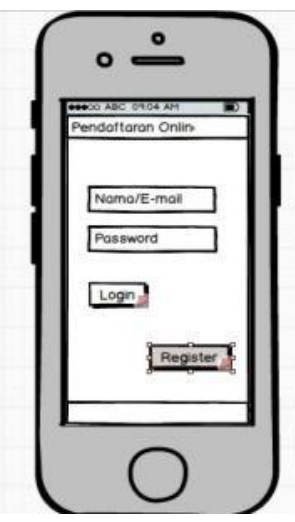

(a)

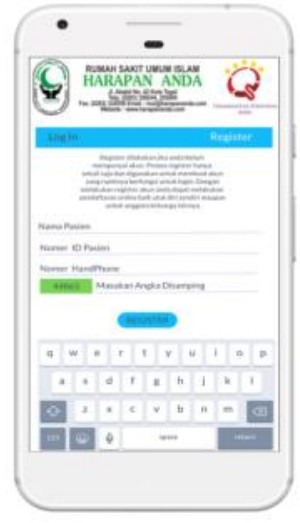

(b)

Gambar 10. Desain proses registrasi akun sebelum (a) dan setelah dievaluasi (b)

\section{KESIMPULAN}

Berdasarkan hasil analisis dan perancangan desain sistem pada bab sebelumnya dapat diambil kesimpulan sebagai berikut: (1). Desain sistem pendaftaran online yang dibuat adalah pendaftaran dalam hal pendaftaran antrian pada layanan poliklnik yang memberikan informasi nomer antrian dan perkiraan waktu kapan nomer antrian dilayani; (2). Desain sistem pendaftaran online berbasis smartphone pada layanan poliklinik bisa digunakan oleh pasien 
menggunakan smartphone pribadi untuk melakukan pendaftaran dalam rentang waktu satu hari; (3). Desain sistem pendaftaran online berbasis smartphone pada layanan poliklinik membuat proses antrian menjadi efektif karena memiliki fitur notifikasi dimana ketika tiga nomer antrian terdekat akan terpanggil, tentunya ini memberikan kemudahan bagi pasien untuk mendaftar dan mengatur antrian.

\section{SARAN}

Saran-saran yang seharusnya dilakukan adalah sebagai berikut: (1). Untuk penerapan aplikasi perlu sosialisasi pada pasien poliklinik RSUI Harapan Anda; (2). Perlu adanya petugas admin yang terlatih dan terpercaya untuk menjaga aplikasi; (3). Untuk pengembangan sistem selanjutnya diharapkan pendaftaran bisa dilakukan lebih dari satu hari

\section{DAFTAR PUSTAKA}

[1] Kemenkes RI, “Klasifikasi Rumah Sakit," p. 116, 2010.

[2] J. G. Barnes, "Secrets of Customer Relationship Management (Rahasia Manajemen Hubungan Pelanggan)," Yogyakarta Andi, 2003.

[3] E. Haryanto, "Queuing System Dengan Voice Untuk Rumah Sakit," J. Tek., vol. 5, no. 2, pp. 114-153, 2015.

[4] A. Esti, Y. Puspitasari, and A. Rusmawati, "Pengaruh Waktu Tunggu dan Waktu Sentuh Pasien Terhadap Tingkat Kepuasaan Pasien Poli Umum Di Puskesmas Sukorame Kota Kediri,” Str. J. Ilm. Kesehat., 2013.

[5] D. A. dan J. D. Gusriyanti, “Koperasi Tanjung Sari," J. Manaj. Sist. Inf., vol. 3, no. 1, pp. 936-951, 2018.

[6] dan R. R. A. Dennis, BH. Wixom, Systems Analysis and Design Fourth Edition. New York: John Wiley and Sons, Inc., 2009.

[7] K. Peffers, T. Tuunanen, M. A. Rothenberger, and S. Chatterjee, "A Design Science Research Methodology For Information Systems Research,” J. Manag. Inf. Syst., 2007. 